\title{
Berwirausaha Melalui Laundry Sepatu di SMP 17 Agustus 1945, Nginden Semolo, Menur Pumpungan, Kota Surabaya
}

\author{
DOI: https://doi.org/10.32509/abdimoestopo.v5i1.1581 \\ Sri Budi Kasiyati ${ }^{1 *}$, Endang Setyowati ${ }^{2}$, Rudi Santoso ${ }^{3}$ \\ Fakultas Ekonomi Bisnis, Universitas 17 Agustus 1945 Surabaya \\ Jl. Semolowaru No.45, Menur Pumpungan, Surabaya, Indonesia 60118 \\ *Email Korespondensi: k_sribudi@ untag-sby.ac.id
}

\begin{abstract}
Shoe laundry is one of the service businesses whose business growth is currently developing and is still relatively new compared to other laundry services. The emergence of this business cannot be separated from the consumptive nature of the community regarding their interest in sneakers and sneakers. This is supported by busy work at the office and on campus, making a person not have enough time to wash his shoes. Due to the limited number of job opportunities and increasing unemployment, from an early age the student community needs to be equipped with various business skills. The aim is to equip Partners (teachers and students of SMP 17 August 1945) who feel they need to receive training on shoe washing and entrepreneurship counseling, so that they have the knowledge, abilities and other skills that can be used later after they graduate for entrepreneurship. Entrepreneurship training and debriefing methods are carried out through the Zoom platform to 19 partners on June 29, 2021. In addition, it is hoped that through this program new entrepreneurs (shoe laundry business) will be created with a minimum net income of IDR 5,000,000,- million per month.
\end{abstract}

Keywords: the shoe laundry, entrepreneur, business, 17 Agustus 1945 Junior High School

Abstrak - Bisnis laundry sepatu adalah usaha jasa yang sedang tumbuh dan berkembang saat ini dan merupakan bisinis baru dibandingkan dengan jasa laundry lainnya. Masyarakat yang konsumtif dan tingginya minat terhadap sepatu jenis Kets dan Sneakers, menciptakan adanya bisnis ini. Hal ini ditunjang oleh kesibukan di kantor maupun di kampus, menyebabkan seseorang tidak mempunyai banyak waktu untuk mencuci sepatunya. Sempitnya lapangan pekerjaaan dan meningkatnya pengangguran, maka sejak dini masyarakat pelajar perlu mendapat pembekalan tentang berbagai keterampilan bisnis. Tujuannya untuk membekali Mitra (guru dan pelajar SMP 17 Agustus 1945) yang dirasa perlu mendapat pelatihan tentang mencuci sepatu dan penyuluhan kewirausahaan, agar mereka memiliki pengetahuan, kemampuan dan ketrampilan lain yang bisa dimanfaatkan nantinya setelah mereka lulus untuk berwirausaha. Metode pelatihan dan pembekalan kewirausahaan dilaksanakan melalui platform Zoom kepada mitra sebanyak 19 orang pada tanggal 29 Juni 2021. Selain itu diharapkan melalui program ini nantinya akan tercipta wirausaha baru (bisnis laundry sepatu) dengan pendapatan bersih minimal Rp 5.000.000,- juta tiap bulan.

Kata Kunci: laundry sepatu, wirausaha, bisnis, SMP 17 Agustus 1945 


\section{PENDAHULUAN}

Bisnis laundry sepatu adalah usaha jasa yang sedang tumbuh dan berkembang saat ini dan merupakan bisinis baru dibandingkan dengan jasa laundry lainnya. Masyarakat yang konsumtif dan tingginya minat terhadap sepatu jenis Kets dan Sneakers, menciptakan adanya bisnis ini. Bisnis adalah kegiatan ekonomis (Asalya P.N:2019) dan (Fitriatun E:2019). Bisnis merupakan aktivitas perdagangan, tetapi didalamnya meliputi pula unsur-unsur yang lebih luas, yaitu pekerjaan, profesi, penghasilan, mata pencaharian dan keuntungan, serta dilakukan baik oleh perorangan maupun perusahaan (Silalahi:2020). Bisnis dapat dilakukan di mana saja dan oleh siapa saja (Umar et al:2016). Sementara Jasa adalah sesuatu yang dapat ditawarkan kepada pasar untuk diperhatikan, digunakan serta dapat memuaskan pelanggan yang membutuhkan jasa tersebut (Wirtz, J., \& Lovelock, C. 2021)

Berbagai Inovasi baru ditawarkan oleh Pebisnis jasa laundry sepatu agar menarik perhatian calon konsumennya. Hal ini ditunjang oleh kesibukan di kantor maupun di kampus, menyebabkan seseorang tidak mempunyai banyak waktu untuk mencuci sepatunya. Bisnis ini memiliki peluang di daerah perumahan, para mahasiswa dan di pusat perbelanjaan.

Bisnis ini memiliki peluang yang besar nampak dari pertumbuhannya pada saat ini. Terdapat sekitar 55 tempat usaha laundry sepatu (hasil datta google maps) di Surabaya. Bagi orang yang memiliki hobi mengoleksi sepatu, membeli sepatu bukanlah investasi yang murah. Tentu saja semua orang ingin memlihara sepatunya agar lebih tahan lama, tentunya melalui jasa laundry sepatu. Pada dasarnya yang membedakan dalam membersihkan sepatu, adalah cara menyikat. Di laundry sepatu ada mesin pengering dan menggunakan mesin steam. Biasanya waktu paling lama pencucian sepatu adalah 3 (tiga) hari kerja.

SMP (Sekolah Menengah Pertama) 17 Agustus 1945 adalah lembaga pendidikan yang berlokasi di wilayah Surabaya Timur. SMP ini memiliki visi sebagai berikut: (1) Memajukan karakter peserta didik melalui proses yang terus menerus dan berkelanjutan; (2) Mengantarkan peserta didik berkemampuan IPTEK dan IMTAQ; (3) Mempersiapkan peserta didik agar menjadi manusia yang berkepribadian, berkualitas di bidang ilmu pengetahuan, olahraga, dan seni; (4) Mengantarkan peserta didik berketrampilan teknologi informasi dan komunikasi serta mampu mengembangan diri secara mandiri; (5) Mengantarkan peserta didik berwawasan nasional dan global serta memiliki jati diri agamis dan nasionalis; (6) Membangun SMP 17 Agustus 1945 sebagai sekolah favorit di Surabaya dan unggul berbudaya. Dalam usaha ikut serta dalam mencapai visi ke tiga, maka Tim Fakultas Ekonomi Bisnis, Universitas 17 Agustus 1945 (UNTAG) Surabaya memberi pelatihan ketrampilan Shoe Laundry. Mitra dalam program ini adalah pelajar dan guru SMP 17 Agustus 1945 yang perlu mendapat pelatihan tentang mencuci sepatu (shoe laundry) dan penyuluhan kewirausahaan. Kewirausahaan merupakan usaha kreatif yang dibentuk berdasarkan inovasi untuk menciptakan sesuatu yang baru, memiliki nilai tambah, memberi manfaat, menciptakan lapangan kerja dan hasilnya berguna untuk orang lain (Rofik A : 2017)

Lokasi mitra berjarak 100 meter dari kampus Universitas 17 Agustus 1945 (UNTAG) Surabaya. Pelatihan dilakukan secara virtual dalam jaringan internet. Program pengabdian ini diawali dengan melakukan justifikasi permasalahan. Untuk memperoleh justifikasi permasalahan, maka dilakukan survei pendahuluan, sehingga bisa diketahui ketrampilan dan pengetahuan yang dibutuhkan oleh mitra program, yaitu pelajar SMP 17 Agustus 1945 Surabaya. Selanjutnya, mitra diberikan pengenalan tentang kewirausahaan dan keterampilan untuk melakukan usaha cuci sepatu. Materi yang didapatkan oleh mitra meliputi ilmu mencuci sepatu yang diawali dengan mempelajari masalah sepatu, peralatan bisnis cuci sepatu, bahan pembersih atau cleaner yang digunakan untuk mencuci sepatu, dan cara mencuci sepatu yang tepat sesuai dengan bahan pembuatan sepatu. 


\section{METODE PELAKSANAAN}

Program pengabdian kepada masyarakat ini dilaksanakan oleh 3 (tiga) orang Dosen dan dibantu oleh 2 (dua) orang mahasiswa Fakultas Ekonomi Bisnis, Universitas 17 Agustus 1945 (UNTAG) Surabaya. Pelaksana program memiliki bidang keahlian yang saling mendukung materi wirausaha jasa cuci sepatu ini. Bidnag keahlian tersebut diantaranya adalah Manajemen Sumber Daya Manusia, Manajemen Pemasaran Kewirausahaan, dan Manajemen Operasional.

Pelaksanaan program pengabdian kepada masyarakat ini dapat digambarkan melalui diagram alir sebagai berikut:

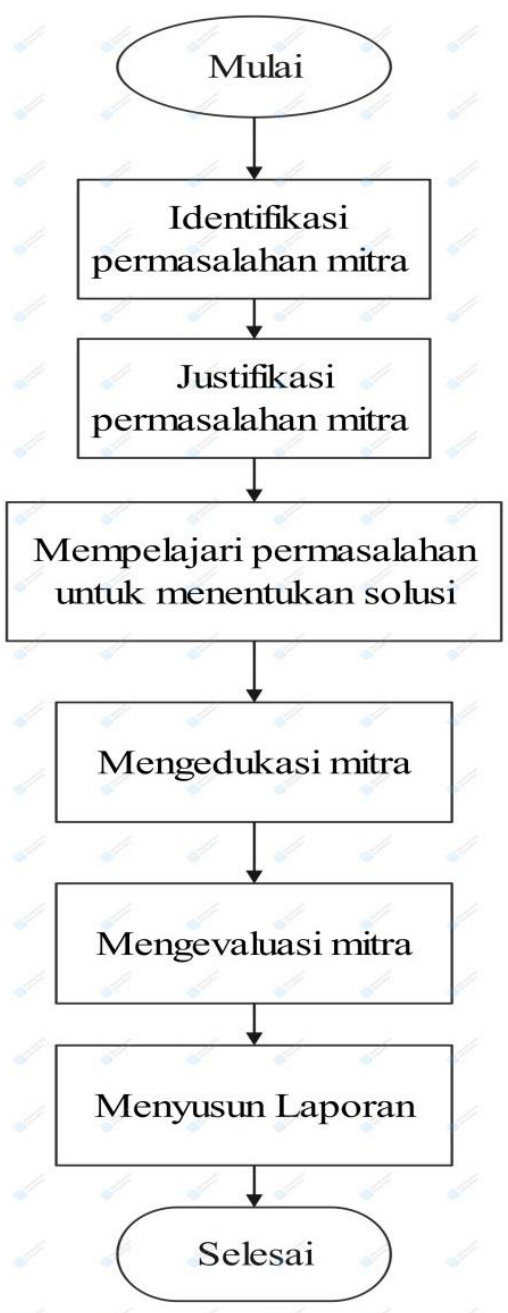

Gambar 1: Diagram Alur Pengabdian kepada Masyarakat

Pelaksanaan pengabdian ini diawali dengan mengidentifikasi permasalahan yang sedang dihadapi oleh mitra. Permasalahan yang sedang dihadapi saat ini oleh masyarakat pada umumnya adalah semakin sempitnya lapangan pekerjaaan dan meningkatnya pengangguran. Berdasarkan data Kemenaker per 20 April 2020, terdapat 2.084.593 pekerja dari 116.370 perusahaan dirumahkan dan kena PHK akibat pandemi Covid-19. (Y. Sri Susilo: 81: 2021) Pengabdian ini diharapkan dapat menjadi langkah preventive bagi mitra ketika lulus dari SMP 17 Agustus 1945 dan terjun ke dunia masyarakat. Untuk itu, sejak dini pelajar perlu mendapat pembekalan tentang berbagai keterampilan usaha, salah satunya adalah laundry sepatu. Pelatihan yang relatif singkat ini bertujuan meningkatkan pengetahuan dan 
keterampilan mereka (Batubara $\mathrm{R}$ et al :2021). Mereka membutuhkan motivasi dan inspirasi mengenai peluang usaha dengan memanfaatkan potensinya. (Suraya S;\&Sulistyo P.B:2019)

Justifikasi permasalahan dilakukan melalui survei pendahuluan, sehingga dapat diketahui keterampilan dan pengetahuan yang dibutuhkan oleh mitra. Laundry sepatu adalah keterampilan yang memerlukan ketelatenan dan kemampuan menggunakan sikat untuk membersihkan atau mencuci sepatu dan memiliki keterampilan dan pengetahuan khusus seputar bahan sepatu. Menurut Alma (24:2013) berwirausaha adalah orang yang melihat adanya peluang kemudian menciptakan sebuah organisasi untuk memanfaatkan peluang tersebut atau setiap orang yang memulai sesuatu bisnis yang baru. Berdasarkan hal ini, tim pengabdian UNTAG mengundang seorang instruktur dan sekaligus sebagai anggota pengabdian ini yang memahami bisnis laundry sepatu.

Pengetahuan pertama yang diberikan oleh instruktur kepada mitra adalah ilmu mencuci sepatu. Hal ini diawali dengan mempelajari masalah yang timbul pada penggunaan dan cara membersihkan sepatu, mulai dari klasifikasi bahan sepatu, perawatan sepatu, bahan pembersih sepatu, dan cara mencuci sepatu yang tepat. Instruktur memberikan praktek melalui media virtual dalam jaringan. Sebelum memberikan materi kepada mitra, instruktur membuat educational video terlebih dahulu yang selanjutkan diputar ketika virtual meeting dengan mitra.

Selain pengetahuan utama tentang laundry sepatu, mitra juga diberikan edukasi tentang kewirausahaan. Hal ini bertujuan untuk mengembangkan pola pikir bisnis dan inovatif untuk mendalami ide bisnis, menginisiasi keterampilan praktis serta struktur yang dapat mereka gunakan untuk mengembangkan, mengevaluasi, dan menguji ide bisnisnya. Selain itu juga untuk membantu mengembangkan keterampilan terkait pasar, membuat jaringan, dan mengakses teknologi, membantu siswa melihat peluang dan memahami kebutuhan masyarakat serta mengembangkan strategi bisnis yang layak dan menawarkan nilai bagi pelanggan dan peluang pasar.

Evaluasi kepada mitra dilakukan melalui diskusi dan tanya jawab untuk mengukur kedalaman materi yang telah diberikan. Evaluasi dilakukan terhadap 15 (lima belas) siswasiswi SMP 17 Agustus 1945.

\section{HASIL DAN PEMBAHASAN}

Pengabdian dilaksanakan pada tanggal 29 Juni 2021 dengan peserta 15 (lima belas) orang pelajar dan 4 (empat) orang guru SMP 17 Agustus 1945. Program pengabdian kepada masyarakat ini dilaksanakan secara virtual karena masih dalam masa pandemi Covid-19. Materi disampaikan oleh tim pengabdian sesuai dengan bidang keahlian masing-masing. Materi pertama adalah kewirausahaan. Pemberian materi ini bertujuan untuk mengembangkan pola pikir bisnis dan inovatif, mendalami ide bisnis, menginisiasi keterampilan praktis dan struktur yang dapat mereka gunakan untuk mengembangkan, mengevaluasi, dan menguji ide bisnisnya. Selain itu juga untuk membantu mengembangkan keterampilan terkait pasar, membangun jaringan, dan mengakses teknologi, membantu siswa melihat peluang dan memahami kebutuhan masyarakat dan mengembangkan strategi bisnis yang layak dan menawarkan nilai bagi pelanggan dan peluang pasar.

Mitra (gambar 2) juga mendapatkan topik kurikulum singkat kewirausahaan yang terdiri dari 8(delapan) poin penting, yaitu:(1)Pengantar kewiarausahaan;(2)Karakteristik kewirausahaan dan pola pikir inovator;(3)Menemukan ide bisnis; (4)Pemasaran, media, dan relasi dengan pelanggan; (5)Operasi bisnis yang terdiri dari kegiatan, sumber daya, dan mitra kunci;(6) Pendapatan dan struktur biaya;(7)Menyajikan Business Model Canvas;(8)Langkahlangkah kewirausahaan. 
Pemateri juga memberikan materi tentang kelompok wirausaha yang efektif (gambar 3). Hal ini bertujuan agar mitra dapat menjalankan bisnis dengan baik jika harus dilakukan secara joint venture. Bisnis secara patungan ini kadang terasa berat karena terlalu banyak pengendali di dalamnya. Melalui materi ini mitra dapat meminimalisir terjadinya gesekan yang dapat mengakibatkan kegagalan membangun usaha.

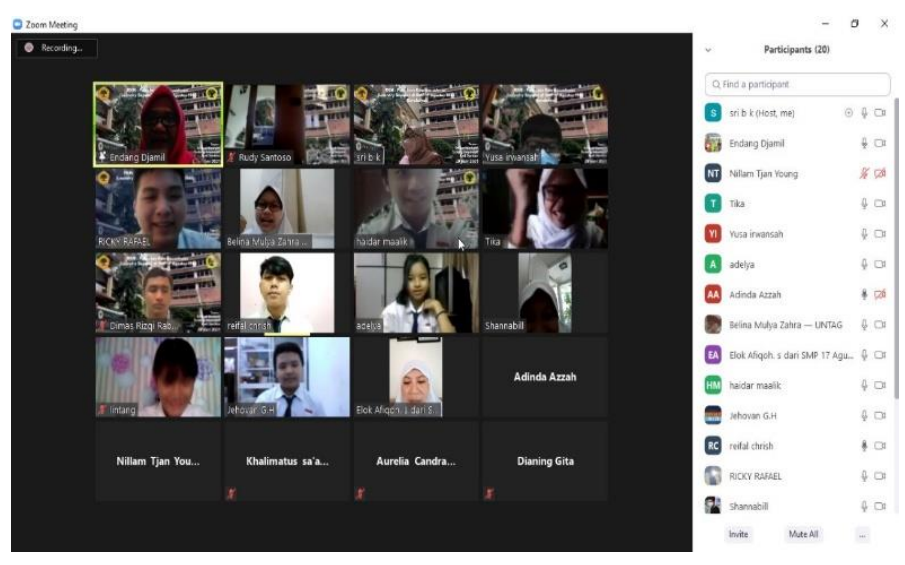

Gambar 2: Pemateri pertama sedang memberikan materi tentang kewirausahaan (Sumber: Dokumentasi pribadi)

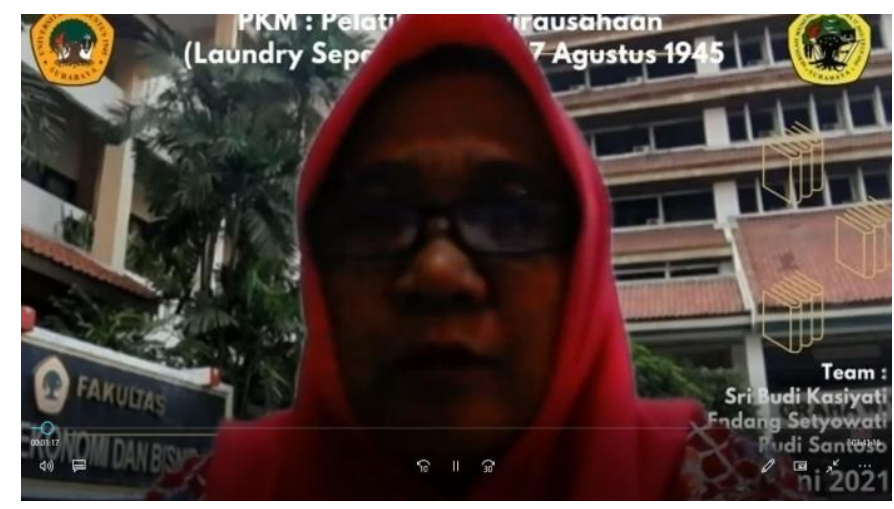

Gambar 3: Peserta sedang mengikuti materi kewirausahaan (Sumber: Dokumentasi pribadi)

Materi ke dua adalah pengenalan laundry sepatu yang menjelaskan tentang identifikasi masalah yang timbul pada penggunaan dan cara membersihkan sepatu, mulai dari klasifikasi bahan sepatu, perawatan sepatu, bahan pembersih sepatu, dan cara mencuci sepatu yang tepat. Identifikasi masalah yang timbul dimulai dengan mengidentifikasi bahan sepatu yang meliputi: (1) Kulit Sintetis. Kulit sintetis adalah bahan sepatu dari campuran bahanbahan kimia olahan pabrik. Bahan kulit sintetis boleh dicuci dengan metode sederhana. (2) Kulit Suede. Kulit suede adalah bagian dari kulit dengan tekstur yang lebih lembut. Agar dilakukan lebih hati-hati dan memerlukan Teknik sendiri (tidak terlalu membasahi sepatu) untuk proses pencucian sepatu berbahan dasar suede. Karena bahan ini mudah terkelupas. (3) Kulit Asli. Kulit asli biasanya terbuat dari kulit hewan seperti sapi, domba, dan kambing, mungkin juga dari hewan reptil seperti ular dan buaya. Untuk mencuci Sepatu dengan bahan ini agar hati-hati,yaitu tidak terlalu membasahi sepatu. (4) Kulit Buk / bunbuck. Kulit buk hampir sama dengan bahan kulit suede tetapi memiliki tekstur yang lebih kasar. Bahan ini boleh dicuci dengan metode sederhana.(5) Karet. Karet adalah jenis bahan sintetis atau bahan non kulit. Bahan ini boleh dicuci dengan membasahi keseluruhan sepatu. Jika bahan 
karet kotor, mudah untuk dibersihkan. 6) Canvas. Cancas memiliki tekstur yang berserat dan ringan saat dipakai. Cara mencuci bahan canvas harus hati-hati dan tidak dicuci berlebihan (7) Denim. Denim adalah bahan yang mirip canvas dengan tekstur tidak terlalu kasar. Cara mencuci bahan ini tidak boleh berlebihan, harus perlahan dan hati-hati (https://www.osttrading.com/bisnis-laundry-sepatu).

Untuk menunjang bisnis jasa cuci sepatu, maka dibutuhkan peralatan cuci sepatu, salah satunya adalah sikat sepatu. Jenis sikat sepatu antara lain adalah:(1)Sikat Vega Bush TR. (gambar 4) Sikat ini terbuat dari bulu kuda yang dapat membersihkan berbagai jenis bahan sepatu. Bentuk sikat ini mirip sikat gigi. Desainnya dibuat dengan posisi yang memanjang guna mempermudah kita dalam membersihkan area sepatu yang sulit dijangkau. Bagian gagangnya terbuat dari bambu berkualitas, sehingga awet dan kuat. (2) Sikat Boss Soft Brush. (gambar 5) Sikat ini bulunya warna ungu dan sangat lembut. Sehingga sepatu bisa aman dari goresan. Bentuk persegi panjangnya, membuat sikat ini sangat pas untuk digunakan pada bagian upper shoes. Selain digunakan pada sepatu kulit, sikat ini juga untuk sepatu berbahan fabric dan suede.

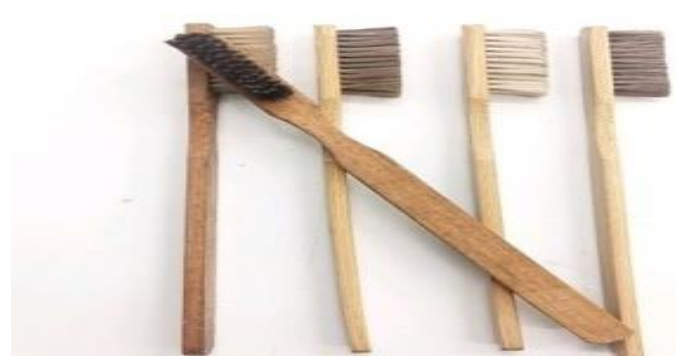

Gambar 4: Sikat Vega Bush TR

(Sumber: https://www.osttrading.com/bisnis-laundry-sepatu/)

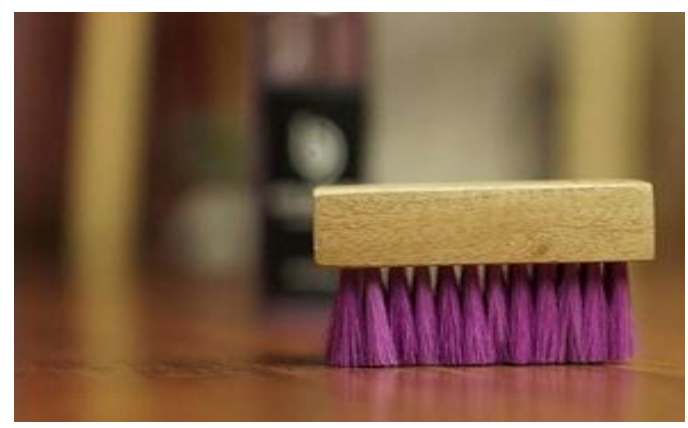

Gambar 5: Sikat Boss Soft Brush

(Sumber: https://www.osttrading.com/bisnis-laundry-sepatu/)

Setelah peserta mengenali jenis sikat dan aplikasinya pada bahan-bahan sepatu tersebut, materi yang mendukung selanjutnya adalah tentang bahan pembersih sepatu. Bahan untuk membuat cairan pembersih sepatu disesuaikan dengan bahan sepatu yang akan dibersihkan, termasuk kategori wet atau dry material. Komposisi cairan pembersih pada sepatu menjadi penting karena menentukan jenis shoes cleaner. Jika air ditambahkan kepencucian, disebut wet shoe cleaner, jika tanpa air, disebut dry shoe cleaner.

Bahan yang digunakan dalam mencuci sepatu meliputi : (1) Sabun cuci sepatu; (2) Deadorant sepatu atau pewangi sepatu; (3) Cairan waterproof.

Setelah mengetahui peralatan dan perlengkapan mencuci sepatu, selanjutnya diberikan materi tentang cara mencuci sepatu yang baik dan benar (gambar 6) sebagai berikut: (1) sol dan tali Sepatu dilepas terlebih dahulu; (2) Kemudian disikat dulu dengan teknik cuci kering bagian luar sepatu (tergantung jenis sepatu), tidak langsung direndam. Terdapat tiga metode 
pencucian yakni berupa Wet clean method, Dry clean method, dan wet and dry method, disesuaikan dengan jenis sepatu. (4) Sol dan tali (bagian dalam) bisa dicuci seperti biasanya. (5) Sepatu tidak boleh dikeringkan langsung di bawah terik matahari dan anginkan atau keringkan pada suhu ruang lebih baik (https://www.osttrading.com/bisnis-laundry-sepatu. Langkah-langkah mencuci sepatu ini dipraktekkan melalui educational video (gambar 7) yang ditampilkan ketika pelaksanaan program pengabdian kepada masyarakat secara virtual.

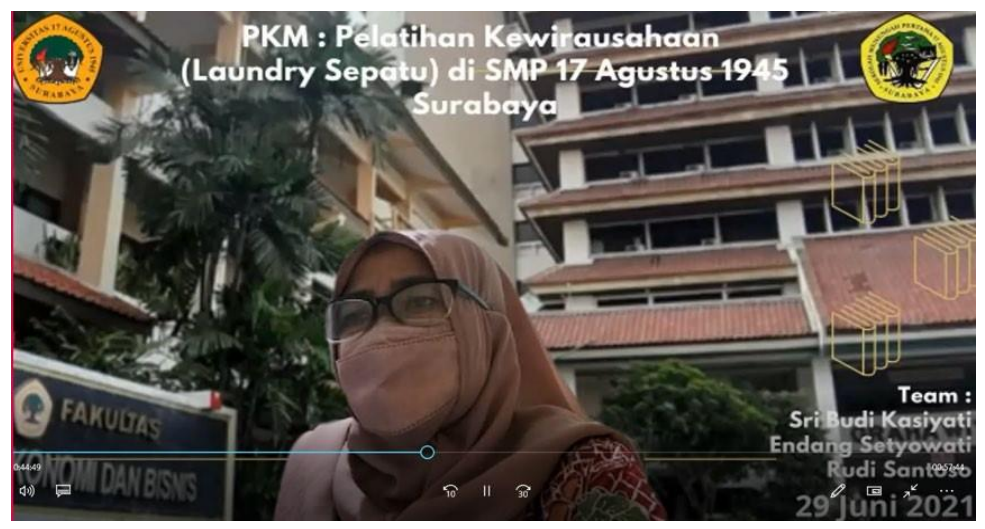

Gambar 6: Pemateri ke dua sedang memberikan materi tentang laundry sepatu (Sumber: Dokumentasi pribadi)

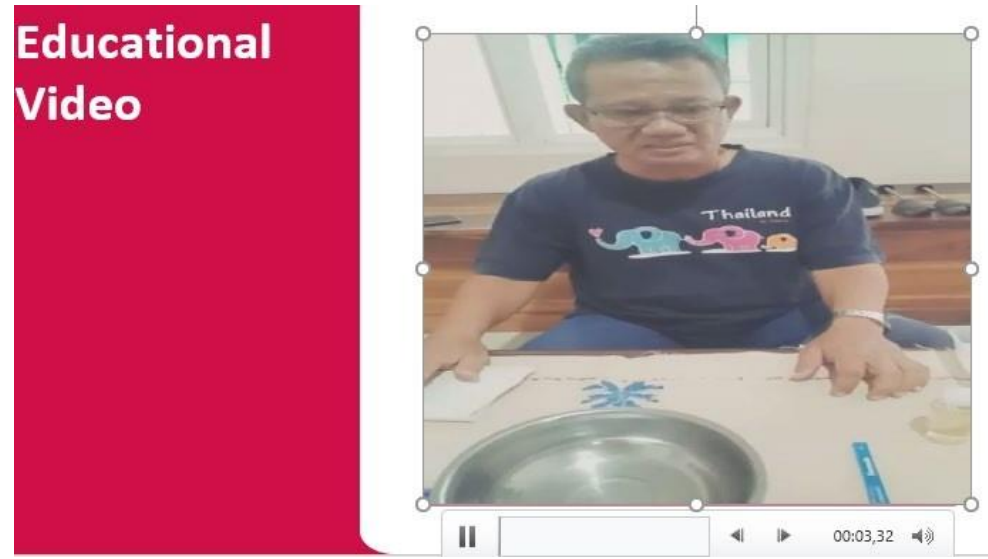

Gambar 7: Pemateri ke tiga sedang mempraktekkan langkah-langkah laundry sepatu (Sumber: Dokumentasi pribadi)

Kelima langkah tersebut merupakan cara umum dalam mencuci sepatu, selanjutnya diberikan juga materi tentang mencuci sepatu berdasarkan bahan sepatu. Pertama adalah cara mencuci sepatu dengan bahan canvas sebagai berikut (1) Untuk menghilangkan kotoran dan debu pada permukaan sepatu gunakan lap lembut; (2) Lepaskan sepatunya;(3) Bilaslah sepatu dengan air hangat. Lakukan di bagian dalam dan luar sepatu; (4) Siapkan larutan air hangat dan 'sabun alami'. Sabun biasa untuk membersihkan sepatu terdiri dari sand soap (sabun kasar untuk membersihkan noda membandel), sabun pencuci piring dan sabun pencuci tangan; (5) Setiap bagian sepatu disikat lembut dan digosok dengan lembut memakai larutan sabun agar tidak merusak permukaan kulit sepatu. Hilangkan noda gores dengan sikat berbulu nilon atau tunggu hingga pelembap sepatu dibubuhkan; (6) Bagian dalam dan luar sepatu dibilas dengan air hangat; (7) Masukkan tisu ke dalam sepatu. Tisu akan menyerap air dan membuat proses pengeringan menjadi lebih cepat. Penggunaan tisu dengan ketentuan sebagai berikut: a) Ganti tisu yang sudah menyerap air dengan tisu baru; b) Memasukkan tisu 
ke dalam sepatu juga membantu menjaga bentuk sepatu ketika kering. (8) Biarkan sepatu mengering. (9) semprotkan FreshLab pewangi laundry setelah kering agar sepatu tidak mudah berbau.

Untuk meningkatkan performa jasa cuci sepatu ini, pemateri juga memberikan beberapa kiat dalam melakukan cuci sepatu berdasarkan bahannya, diantaranya adalah sebagai berikut: (1) Sepatu Kulit, Mulai dengan menggunakan kain lap kering dan lembut untuk membersihkan debu dan kotoran pada kulit sepatu. Campurkan cuka dengan air panas 1:1 dan celupkan ke dalamnya kain pembersih yang lembut. Kemudian usap lembut pada seluruh bagian sepatu dan biarkan mengering dengan di angin-anginkan. Setelah kering lap kembali dengan kain kering yang lembut dan bersih untuk menghilangkan residu. Apabila terdapat lecet, coba gunakan petroleum jelly. Gunakan cotton bud dan oleskan ke bagian yang lecet. Gunakan cairan pembersih kaca untuk mengembalikan kemilau sepatu. (2) Sepatu Suede, Bersihkan dengan menggunakan nail brush (sikat kuku) atau sikat gigi yang sangat lembut dan lakukan penggosokkan dengan satu arah saja agar tidak merusak bahan suede tentunya. Untuk noda pada sepatu, gosok dengan menggunakan penghapus pensil. Bila noda masih bandel alias belum hilang coba gunakan kain pembersih putih dan basahi dengan cuka putih untuk menggosok bagian noda tersebut. Terakhir gosok permukaan kulit suede dengan kain bersih yang sudah dibasahi untuk mencerahkan kembali warna suede sepatu kamu. (3) Sepatu Canvas, Gunakan sikat gigi bekas untuk menggosok permukaan sepatu. Buatlah pasta dari baking soda dan air 1:1, lalu gunakan sikat gigi bekas untuk menggosok pada bagian dasar atau solnya. Kemudian gunakan wadah besar seperti ember atau bak, diisi air dan sabun cair pembersih atau sampo. Lepaskan tali sepatu dan bersihkan dalam wadah berisi sabun tadi. Begitu pula sepatu canvas kamu namun jangan rendam sepatu, cukup celup dan gosok dengan sikat. Gunakan spons untuk membilas bagian permukaan sepatu sampai busa hilang. Serap air dengan menekan handuk kering pada sepatu.Kemudian keringkan sepatu. (4) Sepatu Jelly, Gunakan lap atau kain basah untuk menggosok permukaan terlebih dahulu kemudian bagian bawah atau dasar sepatu. Atau gunakan wadah besar dan beri sabun cair pembersih atau sampo. Celupkan sepatu ke dalamnya dan gosok lembut untuk membersihkan kotorannya. Terakhir keringkan sepatu

\section{SIMPULAN}

Usaha jasa laundry adalah bagian dari usaha shoe treatment. Jasa dari perawatan sepatu meliputi Quick clean, Deep clean, Repaint, Recolour dan special treatment serta water proof. Sebelum pandemi, bisnis ini berkembang sangat cepat di Surabaya. Kesibukan di kantor maupun di sekolah membuat sesorang tidak sempat mencuci dan merawat sepatunya. Oleh karena itu, perlu dicuci dan dirawat agar tahan lama, dan nyaman dipakai. Hal yang perlu diperhatikan adalah bahan sepatu dan alat dan bahan harus lengkap dan sesuai guna.

Melalui pelatihan laundy sepatu, diharapkan terciptanya keinginan dari siswa-siswi dan para guru SMP 17 Agustus 1945 untuk mempraktekkan mencuci sepatu yang baik dan benar dan menginspirasi membuka usaha shoe treatment (laundry sepatu). Luaran yang dihasilkan dari program ini adalah terciptanya produk sepatu yang bersih, wangi dan tahan lama sehingga nyawan bersepatu dan memulai usaha laundry sepatu.

\section{Ucapan Terima Kasih}

Terima kasih kepada pihak yang telah terlibat dalam kelancaran pelaksanaan program pengabdian kepada masyarakat ini, khususnya kepada Universitas 17 Agustus 1945 Surabaya sebagai pemberi dana program pengabdian kepada masyarakat dan SMP 17 Agustus 1945 
Surabaya sebagai mitra yang baik dan kooperatif selama pelaksanaan pengabdian kepada masyarakat ini, serta pihak-pihak lain yang terlibat baik secara langsung maupun tidak langsung yang tidak dapat kami sebutkan satu per satu.

\section{Daftar Pustaka}

Alma. (2013). Pendidikan Kewirausahaan. Pendidikan Kewirausahaan Di Perguruan Tinggi, 53(9).

Asalya, P. N. (2019) Analisis Strategi Pengembangan Usaha Laundry Sepatu D'estilo Makassar Dalam Peningkatan Pendapatan (Tinjauan Ekonomi Islam). Skripsi UIN Alauddin Makassar

Batubara, R., Basyuni, M., Iswanto, A. H., Slamet, B., Susilowati, A., Elfiati, D., Ulfa, M., \& Pebriansyah, R. (2021). Pelatihan Pembuatan Produk Kerajinan Berbahan Cabang Kayu Mangrove. ABDI MOESTOPO: Jurnal Pengabdian Pada Masyarakat, 4(01). https://doi.org/10.32509/am.v4i1.1319

Fitriatun, E. (2019). Analisis Strategi Pengembangan Usaha Laundry Sepatu D'Estilo Makassar Dalam Peningkatan Pendapatan. Journal of Chemical Information and Modeling, 53(9).

Silalahi, Champion. (2020). Pengaruh Word of Mouth (WOM) dan Kualitas Pelayanan Terhadap Keputusan Menggunakan Jasa Laundry Sepatu Shoes And Care pada Pelanggan Shoes And Care Store Medan. Medan: Skripsi Universitas Sumatera Utara

Suryana. (2016). Kewirausahaan Pedoman Praktis: Kiat dan Proses Menuju Sukses, Edisi Ketiga. Jakarta: Salemba Empat.

Suraya, S., \& Sulistyo, P. B. (2019). Sosialisasi Identifikasi Peluang Usaha Kelautan dan Perikanan di Pesisir Pantai Sawarna, Lebak Banten. Abdi Moestopo: Jurnal Pengabdian Pada Masyarakat, 2(2), 30-37. https://doi.org/10.32509/am.v2i02.861

Umar, A., Sasongko, A. H., Agusman, G., \& Sugiharto. (2016). Analisa Swot Pada Bisnis Rumahan, Studi Kasus Pada Bisnis Laundry Kiloan. Buletin Bisnis Dan Manajemen, 2(2).

Y. Sri Susilo , (2021) Pandeminomics, Pandemic Bond \& Stimulus Ekonomi, Book Covid 2021-KAFEGAMA86

Wirtz, J., \& Lovelock, C. (2021). Services Marketing. In Services Marketing. https://doi.org/10.1142/y0024

Rofik A. (2017). The marketing strategy of shoe washing services in Surabaya. Jurnal Manajemen Kinerja, 3(2).

https://jurnal.narotama.ac.id/index.php/kinerja/article/view/462 